ROBSON EDER

\title{
O EXERCÍCIO INTERMITENTE MODULA O METABOLISMO LIPIDICO EM RATOS: O FÍGADO COMO ÓRGÃO GERENCIADOR
}

Tese de Doutorado apresentada ao Instituto de Ciências Biomédicas da Universidade de São Paulo; para obtenção do Título de Doutor em Ciências.

Área de Concentração: Biologia Celular e Tecidual

Orientadora:

Prof $^{a}$ Dra. Marília Cerqueira Leite Seelaender 


\section{Resumo}

EDER, R. O exercício intermitente modula o metabolismo lipídico em ratos: o fígado como órgão gerenciador. 95 f. Tese (Doutorado em Ciências). Instituto de Ciências Biomédicas, Universidade de São Paulo, São Paulo, 2009.

A associação de uma série de influências ambientais como dietas com excesso de gordura ou falta de atividade física regular (sedentarismo) são importantes fatores que podem levar ao desenvolvimento da obesidade e dislipidemias. Portanto, a prática de atividade física regular, caracterizada pelo treinamento, mostra-se atualmente como parte de estratégias para combater problemas como dislipidemias. Sabe-se que o aumento do gasto calórico e a melhora no desempenho podem ser atingidos com treinamentos de endurance ou intermitentes, uma vez que ambos levam à alterações fisiológicas e metabólicas semelhantes. O treinamento intermitente é caracterizado pela execução de repetidas sessões de curtos ou longos períodos, preferencialmente de alta intensidade (aproximadamente $100 \%$ do $\mathrm{VO}_{2 \text { máx }}$ ), intercaladas por pausas ou períodos de menor intensidade, visando a recuperação do indivíduo. Dada a importância do fígado no metabolismo lipídico em repouso e no exercício foi nosso interesse avaliarmos o comportamento do fígado frente a oito semanas de treinamento intermitente de alta intensidade e comparar tais alterações às promovidas pelo treinamento de endurance em ratos, com especial atenção a síntese e secreção de VLDL. Os animais foram divididos em três grupos: sedentário (SD), treinamento contínuo (TC) e treinamento intermitente de alta intensidade (TI). Os dois protocolos de treinamento resultaram em menor ganho de peso em comparação com o grupo SD. Ainda o grupo TI apresentou maior secreção de VLDL em comparação aos grupos TC e SD. Além disso, a expressão gênica da MTP, proteína chave na montagem da VLDL e da LPL muscular responsável por catalisar a liberação de TAG da VLDL para captação pelo músculo esquelético demonstrou aumento no grupo TI em comparação ao SD. Tais resultados inferem que o treinamento intermitente modulou o transporte de TAG para a periferia e contribui para um efeito hipotrigliceridêmico após o exercício de alta intensidade.

Palavras-chave: Exercício intermitente. metabolismo lipídico. Fígado. secreção de VLDL. 


\begin{abstract}
EDER, R. Intermittent exercise modulates the lipid metabolism in rats: the as the manager. 95 p. Ph.D. Thesis (Biologia Celular e Tecidual) - Instituto de Ciências Biomédicas, Universidade de São Paulo, São Paulo, 2009.

The combination of environmental influence, including high fat diets and lack of regular physical activity (sedentary lifestyle) are important factors leading to the development of obesity and dyslipidemias. Regular practice of physical activity, characterized by training, appears as important strategy to reduce such problems. Increased caloric expenditure and improvement of physical performance can be reached with endurance or intermittent training since both lead to similar physiological and metabolic adaptations. Intermittent training is characterized by the execution of repeated bouts of physical effort (high intensity, approximately $100 \%$ of VO2max.) Due to the importance of the liver in lipid metabolism during rest and exercise, we examined the adaptations of organ to 8 weeks of high intensity intermittent training, compared with the effect of endurance exercise with special attention to VLDL synthesis and secretion. The animals were randomized into three groups: sedentary (SD), continuous training (TC) and intermittent training (TI). Both training protocols resulted in reduced weight body gain compared with SD, although IT presents higher VLDL secretion, compared with TC and SD. In addition, gene expression of MTP, a key protein in the assembly of VLDL and LPL muscle responsible for catalyzing the release of TAG for VLDL uptake by skeletal muscle, showed an increase in TI compared to SD. These results suggest that intermittent training modulated the transport of TAG to the periphery and contributed to an hypotriglyceridemic effect caused by high intensity exercise.
\end{abstract}

Key words: Intermittent exercise. Lipid metabolism. Liver. VLDL secretion. 


\section{Introdução}

Atualmente a obesidade é um dos sérios problemas de saúde pública mundial. No Brasil reconhecidamente um pais em desenvolvimento, a obesidade tornou-se rapidamente o principal problema de desordem nutricional, atingindo o posto que até então era ocupado pela desnutrição (BOSSAN et al., 2007).

O sobrepeso ou a obesidade com acumulo de gordura visceral estão fortemente relacionados com uma série de doenças crônicas, tais como, dislipidemias, hipertensão (WAJCHENBERG, 2000), diabetes, aterosclerose (ROSA et al., 2005), câncer (DIZDAR e ALYAMAÇ, 2004) e esteatose hepática (TOLK et al., 2006). A associação de uma série de influências ambientais como dietas com excesso de gordura ou falta de atividade física regular (sedentarismo) são importantes fatores que podem levar ao desenvolvimento da obesidade (WESTERTERP, 2006).

Dentre os quadros citados acima a dislipidemia é caracterizada por um desequilibrio nos lipídios plasmáticos, ou seja, altas concentrações de lipoproteínas de baixa (LDL) e muito baixa (VLDL) densidade e concentrações diminuídas das lipoproteínas de alta densidade (HDL), além de concentrações supra fisiológicas de triacilglicerol e colesterol no plasma (BARRETS e WATTS, 2003). Assim um quadro dislipidêmico é um importante fator de risco cardiovascular que pode ser diminuído frente o treinamento físico, uma vez que a pratica de atividade física regular atua otimizando processos metabólicos como mobilização, transporte e utilização de gorduras (CHAN et al., 2006).

Dessa forma a pratica regular de exercícios caracterizando o treinamento, apresenta-se como parte de estratégias não farmacológicas no controle da obesidade, ganho de peso e dislipidemias (SARIS et al., 2003). As recentes determinações publicadas pelo American College Sports Medicine determinam que adultos sedentários devam acumular pelo menos 30 minutos diários de atividade física moderada de 3 a 5 vezes por semana, com objetivo de promoção da saúde e prevenção de doenças degenerativas (JAKICIC et al., 2001 e ACSM, 2009).

Ao longo das últimas décadas diversos trabalhos com humanos (COGGAN et al., 1992 e MACDOUGALL et al., 1998) ou modelos animais (SEBURNS et al., 1994; TAKAHASHI et al., 1996 e LIRA et al., 2008) demonstram os benefícios da atividade física na diminuição da gordura corporal, atenuação dos fatores de risco cardiovasculares e 
doenças degenerativas (SIMKO e KELLEY, 1979; DENGEL et al., 1998 e TSEKOURAS et al., 2008).

Além de promover a perda de peso e alterações na composição corporal o exercício é utilizado como indutor de melhoras no perfil lipídico e combate a doenças degenerativas (DENGEL et al., 1998). Em trabalho realizado por nosso grupo, utilizando ratos portadores de tumor de Walker 256, Lira et al., (2008) demonstraram que o exercício de intensidade moderada realizado em esteira 5 vezes por semana foi eficiente em reduzir o peso dos animais e peso do tumor, além de contribuir para o menor acumulo de gordura hepática.

Gauthier et al., (2003) concluíram em seu estudo com ratos treinados durante 8 semanas e submetidos a uma dieta hiperlipídica que o exercício regular diminuiu a gordura visceral e melhorou vários parâmetros como concentração de triacilglicerol (TAG) e ácidos graxos livres (AGL) plasmáticos. Por sua vez, em trabalho com humanos Jacobs et al., (2006), submeteram jovens saudáveis e sedentários a 9 semanas de treino em ciclo ergômetro na intensidade de $65 \%$ do VO2máx., e demonstraram em seus resultados finais, maior concentração de HDL-C e menor de LDL-C no final do treinamento quando comparados com os valores anteriores ao período de treino.

Phillips et al., (1996) submeteram jovens saudáveis, cinco dias por semana, duas horas por dia a exercício em ciclo ergômetro a uma intensidade de $60 \%$ do VO2máx., e verificaram diminuição na utilização de carboidratos e aumento na oxidação de gordura corporal, além de redução na concentração de glicose plasmática em concomitância à melhora de parâmetros cardiovasculares. Em um trabalho clássico Oscai e Holloszy (1969), submeteram ratos com dieta padrão ou restritiva a treinamento em piscina durante 18 semanas, em sessões diárias 120 minutos, com sobrecarga de $1 \%$ do peso corporal e demonstraram que os animais treinados apresentaram perda de peso. Além disso, o treino ofereceu um efeito protetor com relação à perda massa magra no grupo que dieta restritiva e em comparação ao grupo sedentário. Tsekouras et al., (2008) concluíram que o exercício intervalado aeróbio promoveu redução na concentração de VLDL-TAG plasmática em repouso, em 16 jovens não obesos, em conseqüência de menor secreção dessa lipoproteína pelo fígado.

Sabe-se que o treinamento físico de endurance (esforço em intensidade submáxima por período prolongado), exacerba a utilização de lipídios em detrimento da de carboidratos (HOROWITZ e KLEIN, 2000). Ácidos graxos são considerados um importante substrato para esse tipo de esforço. Ainda diferentes opiniões persistem acerca 
das contribuições relativas dos lipídios e carboidratos na manutenção da contração muscular. Muitos autores concordam que a relativa contribuição dos lipídios durante o esforço diminui com o aumento da intensidade do exercício (BROOKS e MERCIER, 1994) enquanto outros autores relatam que a contribuição da oxidação lipídica aumenta com a duração do exercício (TURCOTTE et al., 1992).

Esse tipo de treinamento (50-75\% do volume máximo de oxigênio - $\mathrm{VO}_{2 \text { máx. }}$, e longa duração), promove alterações metabólicas e fisiológicas que permitem a manutenção da atividade por longos períodos, além de retardar a depleção dos estoques de glicogênio, fator que limita a continuação do esforço e conduz à fadiga localizada (COGGAN, 1995 e COGGAN et al. 1995).

Diversos estudos têm demonstrado uma maior capacidade muscular de oxidar ácidos graxos (MOLÉ, 1971; BALDWIN, 1972), corpos cetônicos (WINDER et al., 1974) e piruvato (BALDWIN, 1972), em indivíduos e animais treinados.

Fundamentalmente essa melhora na capacidade oxidativa ocorre simultaneamente a aumentos na concentração e atividade das enzimas responsáveis pela ativação (acil CoA sintetase), transporte (carnitina palmitoil transferase) e beta-oxidação (3-hidroxiacil CoA desidrogenase) de ácidos graxos de cadeia longa, como demonstrada por Molé e col. (1971) e confirmado posteriormente por Baldwin et al., (1972), Jansson, (1987) e Phillips et al., (1996).

As enzimas atuantes no ciclo de Krebs, como malato e succinato desidrogenase, também demonstraram atividade aumentada em função do treinamento (HOLLOSZY, 1967 e 1970; COSTILL, 1979; JANSSON, 1987) e finalmente, as enzimas relacionadas à cadeia de transporte de elétrons, como NADH desidrogenase, NADH citocromo-c redutase e citocromo oxidase, também são afetadas pelo treinamento de endurance (HOLLOSZY, 1967 e HENRIKSSON, 1977).

Sabe-se que o aumento do gasto calórico e a melhora no desempenho podem ser atingidos também com outros tipos de treinamentos. Comparando-se aos de endurance, os treinamentos ditos intermitentes também levam à alterações fisiológicas e metabólicas semelhantes (TREMBLAY et al., 1994 e GIBALLA et al., 2006). O treinamento intermitente é caracterizado pela execução de repetidas sessões de curtos ou longos períodos, preferencialmente de alta intensidade (aproximadamente $100 \%$ do $\mathrm{VO}_{2 \text { máx. }}$ ), intercaladas por pausas ou períodos de menor intensidade, visando à recuperação do indivíduo (BILLAT, 2001). 
Estudos realizados utilizando o modelo intermitente têm mostrado que a variação de intensidade, a duração do trabalho e os períodos de recuperação podem levar a diversas adaptações metabólicas (GAITANOS et al. 1993 e BABINEAU e LEGER, 1997). Esse tipo de treinamento é freqüentemente utilizado nos esportes de alto desempenho como, atletismo, futebol, basquete e tênis (BERGERON, 1990).

Modalidades esportivas praticadas atualmente na sociedade são caracterizadas exercícios intermitentes. Segundo Bergeron et al., (1991) o tênis é um esporte caracterizado como exercício intermitente devido aos sprints de variadas intensidades e numerosos períodos de recuperação, no entanto, segundo o autor o entendimento de suas demandas energéticas e metabólicas permanecem obscuras por causa dos poucos estudos realizados com esse esporte. Além do tênis, o futebol é outro esporte muito praticado na sociedade ocidental e também é marcado por períodos de alta intensidade seguidos de caminhadas durante as partidas (BANGSBOO et al., 1991). Diversos autores defendem o aumento na pratica de esportes na sociedade como solução no combate ao sedentarismo, uma vez que a pratica de esportes geralmente é acompanhada de maior entusiasmo e engajamento (BERGERON, 2007).

A dificuldade para caracterizar o tipo de atividade realizada durante a prática de esportes, fez com que diversos autores utilizassem estratégias para mimetizar o esforço aplicado nas varias modalidades (GLAISTER, 2005). Contudo, devido à variedade de protocolos empregados, sabe-se pouco sobre treinamentos que utilizam exercícios intermitentes de alta intensidade caracterizado em vários esportes e sua relação com o metabolismo de lipídios. Em um estudo clássico Essen (1978), demonstrou que o treinamento intermitente (112\% do VO2max., durante 60 minutos com relação exercício/recuperação de 15 segundos) impediu a depleção dos estoques de glicogênio, em decorrência de uma maior contribuição de lipídios, quando comparado com o exercício contínuo (102\% VO2max. mantido entre 4-6 minutos), ambos realizados à mesma velocidade. Segundo o autor, após 60 minutos do treinamento intervalado, as fibras tipo I (oxidativas) e II (predominantemente glicolítica) contribuíram de modo semelhante na oxidação de substratos, enquanto que no exercício contínuo a depleção de glicogênio foi maior nas fibras tipo II .

Chilibeck e col. (1998), aplicando um modelo de treinamento de exercícios intermitente e contínuo em roedores por 12 semanas, demonstrou que os treinos intervalado e contínuo aumentaram a razão de oxidação de ácidos graxos nas mitocôndrias subsacolermais e intermiofibrilares, comparando os dois protocolos com o grupo controle. 
A oxidação de palmitoil foi significantemente maior no grupo submetido ao treinamento intermitente quando comparado com o treinamento contínuo. De acordo com Tremblay et al. (1994), vinte indivíduos treinados de forma intermitente e a alta intensidade mostraram elevação na concentração das enzimas 3-hidroxiacil CoA desidrogenase e malato desidrogenase relacionadas com a beta-oxidação e ciclo de Krebs, respectivamente, demonstrando maior atividade em indivíduos treinados com exercícios intermitentes quando comparados com o treinamento continuo. Além disso, o treinamento intermitente levou a uma maior redução nas medidas das dobras cutâneas.

Talanian et al., (2007) submeteram 8 mulheres a sessões diárias de 4 minutos de exercício (ciclo ergômetro) a 90\% do VO2 máx., com intervalos de 2 minutos de recuperação durante 2 semanas e relataram aumento nas proteínas beta-hidroxi-acil-CoA desidrogenase, LHS e FABP, em comparação com os valores encontrados antes das duas semanas de treinamento.

Burgomaster et al., (2008), dividiram 20 jovens saudáveis em dois grupos e aplicaram um protocolo de exercício moderado (40-60 min./60\% VO2 máx./5 x semana/ $2250 \mathrm{Kj} / \mathrm{sem}$.) ou intermitente de alta intensidade (4-6 tiros de 30 segundos: 4 min de intervalo/ 100\% VO2máx./3 x semana/225 Kj/sem.), durante 6 semanas e demonstraram a mesma taxa de oxidação de carboidratos e lipídios durante as sessões. O grupo concluiu que o grupo intermitente mostrou-se time-efficient, em comparação ao grupo contínuo, ou seja, resultados semelhantes podem ser alcançados em um menor tempo de atividade realizada à altíssimas intensidades. A autora citada acima faz parte do grupo liderado pelo professor Martin Gibala, o qual defende amplamente em vários trabalhos (RAKOBOWCHUK et al., 2008; BURGOMASTER et al., 2008, GIBALA et al., 2009 e GIBALA eMCGEE, 2008) essa estratégia como solução para a "falta de tempo" na sociedade ocidental (GIBALA, 2007). Na maior parte dos estudos que utilizam exercícios intermitentes de alta intensidade são abordados o metabolismo de carboidratos e alterações cardiovasculares, são poucos, entretanto, os estudos que relacionam exercício intermitente de alta intensidade e metabolismo lipídico.

Ainda, a maioria dos trabalhos que envolvem treinamento, exercício e desempenho encontrados na literatura têm como principal órgão estudado o músculo esquelético.

Contudo, sabe-se que não apenas o músculo esquelético é afetado e sofre adaptações fisiológicas, metabólicas ou morfológicas em decorrência do exercício. Outros 
tecidos como o adiposo e órgãos como rins (FREUND et al., 1991), coração (LEVINE, 2008 e THOMPSON et al., 2007), pulmões (CALBET et al., 2008) entre outros também estão metabolicamente ativos e contribuem para a manutenção do esforço. Entre os órgãos que respondem à atividade física o fígado aparece como o gerenciador do metabolismo intermediário e fornecedor de substratos energéticos para os tecidos periféricos em situações de repouso ou exercício (GORSKI, 1990 e SPASSIANI e KUK, 2008).

O fígado tem papel importante no metabolismo dos macro nutrientes como os carboidratos, sendo sítio da via de síntese de pentoses (via das pentoses-fosfato) e sintetizando (glicogênese) e degradando (glicogenólise) glicogênio hepático (KJAER, 1998, GALASSETTI et al., 1999 e SUH e JACOBS 2007). Ainda em relação às proteínas e aminoácidos etapas importantes de síntese protéica mediada pela insulina, além da degradação, durante o exercício, sinalizada pelo glucagon (gliconeogenese), são processos que ocorrem no tecido hepático (BROOKS, 1987). Não obstante o próprio ciclo da uréia e posterior eliminação da amônia ocorrem nesse órgão (WASSERMAN e CHERRINGTON, 1991 e VIRU, 1987).

O fígado exerce um papel central na distribuição de substratos para os tecidos periféricos. O órgão é o responsável pela determinação das concentrações plasmáticas de TAG, AGL, colesterol e lipoproteínas (MCGARRY e FOSTER, 1980). O tráfego de lipídeos é bidirecional, organizado sob uma série de condições fisiológicas e tem seu balanço estabelecido pelas concentrações de lipídeos que são secretados pelo fígado, captados ou liberados pelos tecidos periféricos e re-captados pelo próprio (ZAMMIT, 1996).

A origem específica dos lipídios estocados no fígado permanece incerta. As potenciais fontes que contribuem para isso ao lado da lipogênese, incluem ácidos graxos liberados pelos tecidos periféricos no sangue via lipólise (AGL) e gorduras provenientes da dieta, as quais chegam ao fígado derivadas do quilomicron após absorção intestinal (HAVEL e HAMILTON, 2004).

Nos hepatócitos os lipídeos podem seguir por rotas diferentes (partição), estabelecidas pelo estado fisiológico e metabólico do individuo. No estado pós prandial ou em caso de diabetes (tipo II) as altas concentrações de insulina favorecem a esterificação de ácidos graxos em TAG, tendo sido considerada, a insulina, o principal hormônio estimulador dessa síntese (DUERDEN et al., 1989). A insulina sinaliza a ativação da enzima glicerol-3-fosfato acil-transferase, a qual catalisar o passo inicial da síntese de TAG pelo hepatócitos, por outro lado, altas concentrações do mesmo hormônio ativam a 
enzima acetil-CoA carboxilase, que catalisar a primeira reação para formação da molécula de malonil-CoA, que por sua vez é o principal inibidor da CPT I, enzima limitante no processo de oxidação de ácidos graxos de cadeia longa. Ou seja, os processos de síntese de TAG e degradação de AGCL, também ocorrem no fígado e são mediados pelo estado fisiológico do individuo (TOPPING e MAYES, 1982).

Ainda, em casos de resistência à insulina ou diabetes tipo II, ocorre no tecido adiposo uma incompleta inibição da enzima lípase hormônio sensível o que acarreta em aumento da lipólise e maior concentração plasmática de ácidos graxos, consequentemente maior infiltração lipídica no fígado (MACHADO e CORTEZ, 2005). Portanto, o comportamento do fígado diante de algumas desordens metabólicas faz-nos crer que sua capacidade de captação e estoque esta relacionada as concentrações plasmáticas de lipídeos. A plasticidade hepática confere a esse órgão a função de armazenamento, com objetivo de neutralizar a toxidade dos ácidos graxos liberados pelo tecido adiposo ou provenientes de dietas hiperlipídica (UNGER et al., 1999).

Não obstante, a síntese de ácidos graxos de novo e o armazenamento em decorrência da alta concentração plasmática de gordura, o fígado também é grande consumidor de ácidos graxos de cadeia longa (AGCL) para geração de energia no repouso e no exercício (MURTHY e PANDI, 1994).

A Beta-oxidação mitocondrial é a mais importante rota para oxidação de AGCL e influência de forma dominante a partição relacionada ao metabolismo lipídico dentro do fígado. O complexo mitocondrial CPT (CPT I, II e CACT) é o mais bem entendido complexo enzimático de membrana dessa organela celular. A capacidade da enzima CPT I em converter Acil-CoA em acilcarnitina e a catalise inversa promovida pela enzima CPT II na matriz mitocondrial resulta na efetiva transferência da molécula de AGCL para dentro da matriz mitocondrial (ZAMMIT e CORSTORPHINE, 1985). CPT I é uma proteína integral de membrana e localiza-se na membrana externa da mitocôndria, enquanto a CPT II é uma proteína periférica ancorada no lado interno da membrana mitocondrial interna. A CPT I esta sensível à inibição alostérica da molécula de malonil-CoA, tal fato torna a ação da CPT I, o principal sitio de controle para formação da acilcarnitina e beta-oxidação, além de suscetível ao controle promovido pela insulina (WOELTJE et al., 1987).

Malonil-CoA é produto da reação catalisada pela acetil CoA carboxilase, enzima que utiliza acetil-CoA para síntese de ácidos graxos. A insulina é um potente ativador da ACC por meio de uma série de mecanismos como, fosforilação que resulta em ativação da enzima (WITTERS et al., 1988). No exercício, essa regulação é explicada pela baixa 
concentração de insulina, promovida pela maior ativação simpática. Nesse caso a síntese de malonil-CoA esta diminuída e a formação do complexo acilcarnitina aumentado.

Acredita-se que a concentração de malonil-CoA em repouso seja suficiente para inibir a atividade da CPT e que a diminuição em sua concentração poderia elevar o transporte de AGCL para dentro da mitocôndria (SAHA et al., 1995). As concentrações de malonil-CoA diminuem no músculo esquelético com inicio do exercício (endurance) levando a um aumento na produção de energia proveniente de AGCL (ROMJIN et al., 1993). Por outro lado, sabe-se que ocorre maior concentração de acetil-CoA com o aumento da intensidade do exercício, sendo a molécula de acetil-CoA substrato inicial para catalise da ACC. Tal fato explica a menor a captação de AGCL pela mitocôndria durante o exercício de alta intensidade (WINDER et al., 1989). Não obstante, van Loon et al., 2001, relatam que o aumento na concentração de acetil-CoA pode levar à "acetilação" da carnitina em uma reação catalisada pela enzima carnitina acetil transferase (CAT), isso ocorreria em exercícios de alta intensidade onde a taxa de formação de piruvato excederia sua utilização pelo ciclo do acido tricarboxilico (Ciclo de Krebs), o que acarretaria na menor disponibilidade da carnitina e down regulation da CPT I (ODLAND et al., 1998).

Relatos de aumento na atividade das enzimas do complexo CPT e maior oxidação lipídica em decorrência da exercício físico ou treinamento de endurance vem sendo descritos na literatura, no entanto a maioria dos trabalhos trazem como tecido alvo o músculo esquelético (ROMJIN et al., 1995; SIDOSSIS et al., 1998; KIENS e RICHTER, 1998). Assim é bem descrito que a maior atividade do complexo CPT, como adaptação ao treinamento, resulta em maior oxidação lipídica pelo músculo esquelético (RASMUSSEN e WOLFE, 1999).

Por sua vez, no fígado, a regulação da oxidação lipídica é sensivelmente influenciada pelo estado fisiológico do individuo. No hepatócitos o acetil-CoA proveniente da beta-oxidação pode ser utilizado para geração de energia ou formação de corpos cetônicos em uma série de reações do ciclo HMG-CoA, que resultam em acetoacetato ou betahidroxibutirato (MCGARRY e FOSTER, 1980). Na hipoglicemia e durante o exercício a maior produção de corpos cetônicos é agente protetor no organismo contra a proteólise além de fornecer substratos para geração de energia em outros órgãos (WASSERMAN et al., 1989).

Segundo McGarry et al., (1989), em exercícios de intensidade moderada e longa duração o aumento da atividade catalítica do complexo carnitina palmitoil transferase (CPT) e das enzimas envolvidas na beta-oxidação levariam a um excesso de acetil-CoA no 
fígado, tal fato potencializaria a formação de corpos cetônicos e liberação beta hidroxi butirato.

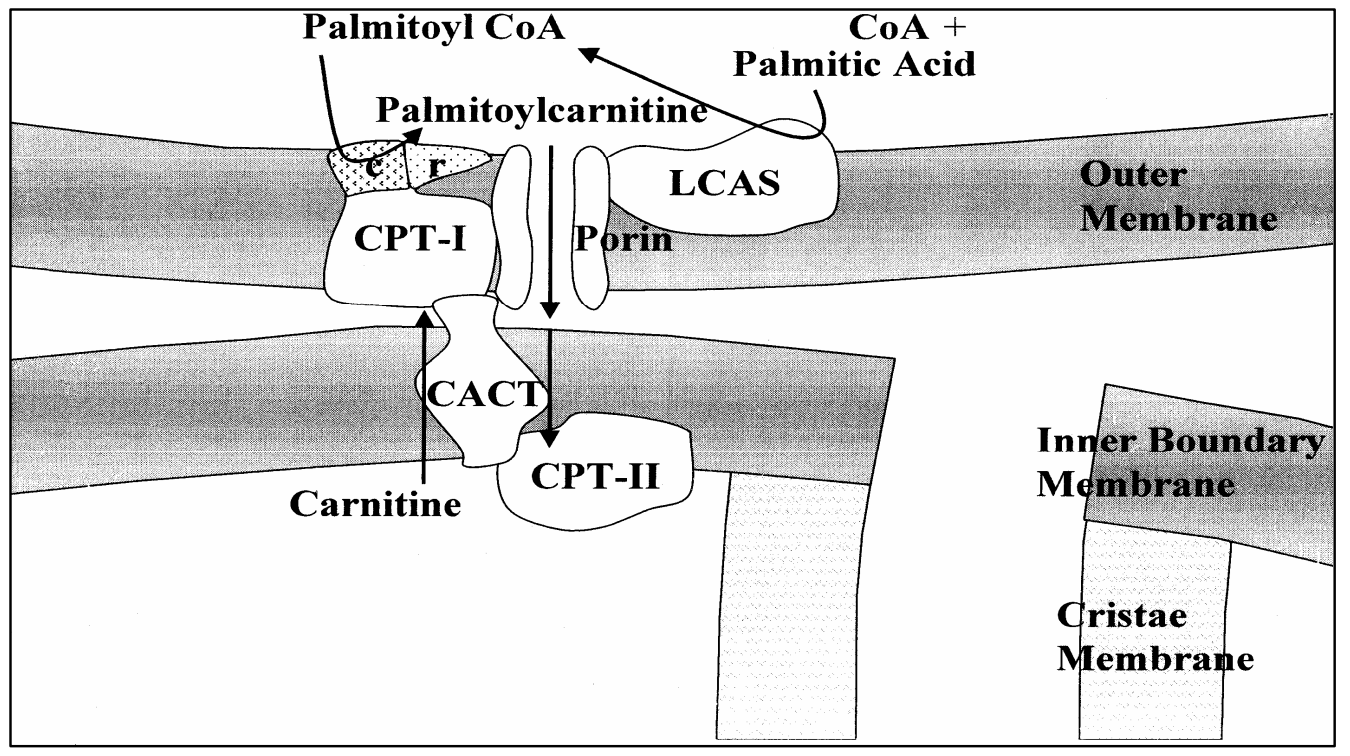

Figura 1. Esquema ilustrativo que demonstra a disposição das proteínas do complexo CPT ao longo da membrana mitocondrial interna e externa retirado de KERNER E HOPPEL, (2000).

O direcionamento do metabolismo lipídico pelo fígado depende das concentrações de ácidos graxos plasmáticos e da formação de ácidos graxos de novo. Os lipídeos contidos nos hepatócitos podem ainda seguir por vias diferentes como, beta-oxidação ou esterificação (ZAMMIT, 1996). Não obstante, o transporte de triacilglicerol e colesterol para os tecidos periféricos também é mediado pelo fígado e é realizado por uma estrutura composta de lipídeos e proteínas conhecidas por lipoproteínas, essas partículas esféricas são compostas de apo lipoproteínas, triacilglicerol, fosfolipídios e colesterol (SHEPHERD, 1992). O fornecimento de triacilglicerol para os tecidos extra-hepáticos dá-se através da lipoproteína de muito baixa densidade VLDL, sendo o tecido adiposo e o músculo esquelético os dois principais receptores (DURSTINE et al., 2002). Além da VLDL, temos ainda a lipoproteína de baixa densidade (LDL) que é uma partícula rica em colesterol e representa uma fração remanescente de VLDL (DURSTINE e THOMPSON, 2001) e a lipoproteína de alta densidade (HDL) cuja função é realizar o transporte reverso de colesterol da periferia para o fígado (SEIP et al., 1993 e STEFANICK et al., 1998). 
Dentre todas as lipoproteínas a VLDL é a única totalmente sintetizada no hepatócitos. A partícula nascente montada e secretada pelo fígado, consiste de uma estrutura globular com diâmetro entre 25 e $75 \mathrm{~nm}$ sendo seu componente hidrofóbico composto de triacilglicerol e pequena quantidade de ésteres de colesterol (ALEXANDER et al., 1976).

A montagem da VLDL é um processo complexo que inicia-se pela mobilização dos depósitos de TAG no citoplasma do hepatócitos pela enzima arilacetamida diacetilase (AADA), os produtos da lipólise são reesterificados, por ação enzimática da diacilglicerol acil transferase II, no lumem do reticulo endoplasmático liso onde formam gotículas de TAG, que por sua vez serão transferidos pela ação da proteína de transporte microssomal (MTP) para a APOB uma proteína intralumenal necessária para produzir a partícula de VLDL intermediaria (GORDON, 1997), sendo a MTP a enzima que desempenha papel chave na montagem dessa lipoproteína (GIBBONS et al., 2004). Finalmente, a maturação total da VLDL, é dependente da ação da fosfolipase D, responsável pela transferência de grandes droplets de TAG, para a partícula intermediaria (ASP et al., 2000). A produção e secreção da VLDL é regulada através da dieta (Windmueller e Spaeth, 1985), por fatores endócrinos (REAVEN e CHEN, 1988) e segundo alguns autores em decorrência do treinamento físico (Magkos et al., 2008). Desse modo a prática de atividade física regular, dentre outro fatores, pode modular a secreção e concentração plasmáticas de lipoproteínas e contribuir para um melhor perfil lipídico (PFEIFFER et al., 2006).

Alguns trabalhos demonstram a influência do treinamento de endurance na secreção e concentração de VLDL. Chapados et al., (2008) em trabalho realizado com roedores submeteram os animais à duas dietas diferentes (padrão e rica em gordura) e submeteram os animais à 8 semanas (5x semana - 60 minutos por dia) de treinamento em esteira em uma velocidade de $26 \mathrm{~m} / \mathrm{min}$., e demonstraram que o treinamento diminuiu a expressão da proteína MTP (chave na montagem da VLDL) além de reduzir a concentração plasmática de VLDL, no grupo submetido à dieta hiperlipídica.

Em outro estudo Alam et al., (2004) verificaram a concentração de VLDL, além de outros parâmetros lipídicos em 18 mulheres obesas e portadoras de diabetes II, elas foram submetidas à 6 meses de atividade física moderada (20-40 min. $-60-85 \%$ do $\mathrm{VO}_{2 \text { máx }}-4 \mathrm{x}$ semana), os autores concluíram que a menor secreção de VLDL ocorreu devido a maior sensibilidade hepática à insulina. A diminuição do fluxo de ácidos graxos livres (AGL) do 
tecido adiposo para o fígado pode indiretamente melhorar a resistência à insulina e diminuir o conteúdo intra-hepático de gordura, assim, tal fato diminuiria a secreção de VLDL (RYYSY et al., 2000).

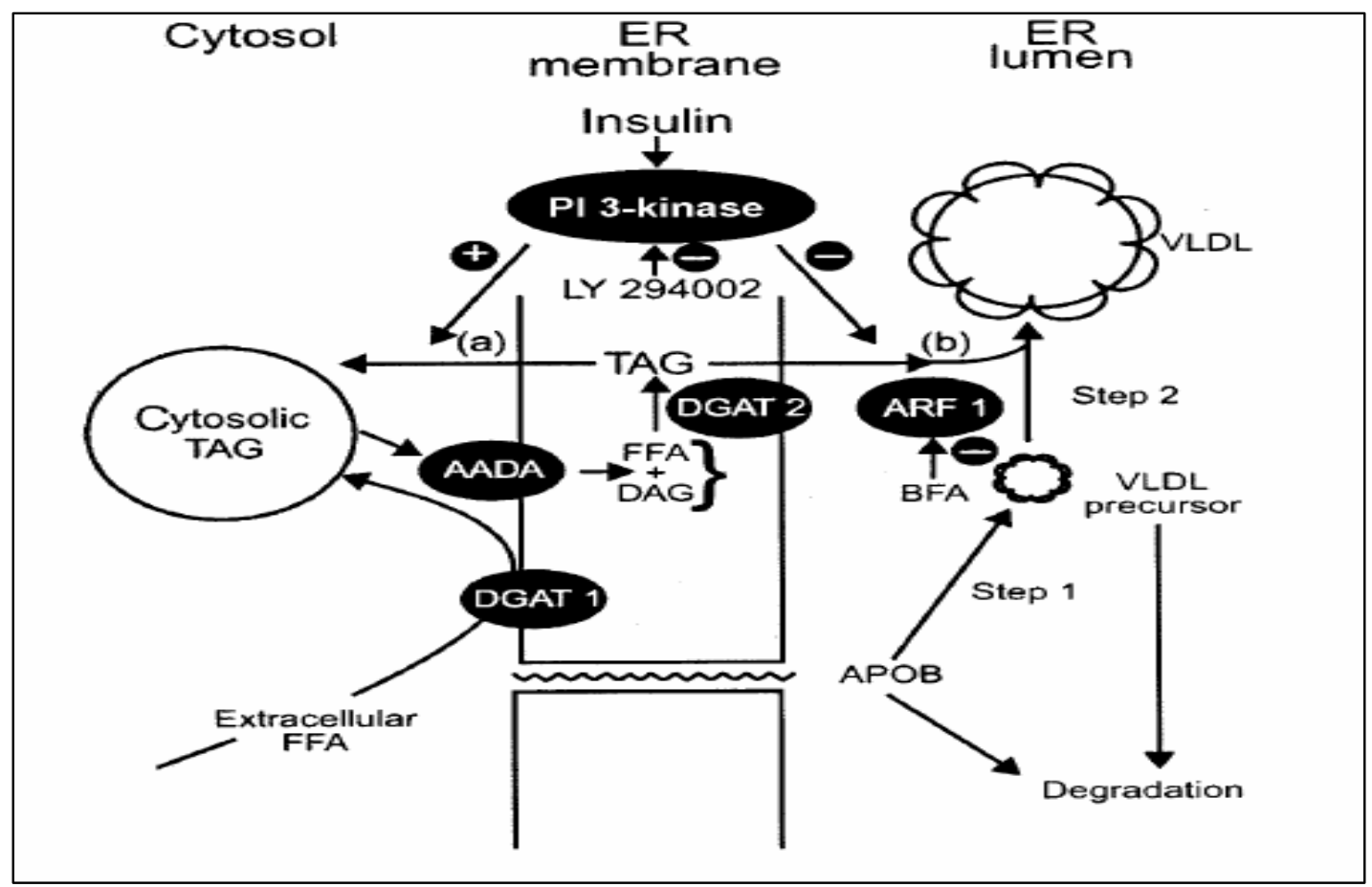

Figura 2. Esquema ilustrativo que demonstra o processo de montagem da VLDL retirado de GIBBONS et al., (2002).

Apesar de poucos trabalhos, a maior contribuição em estudos envolvendo parâmetros do metabolismo lipídico frente à exercícios de alta intensidade vem do grupo coordenado pelo Dr. Labros Sidossis, em Atenas na Grécia, que em trabalhos realizados por seus colaboradores, verificam-se as modulações no colesterol, triacilglicerol e VLDL frente à exercícios de alta intensidade (TSEKOURAS et al., 2008).

Em trabalho, realizado com sete homens saudáveis Makgos et al., (2006) submeteram o grupo a uma sessão simples de exercício moderado em ciclo ergômetro (2 horas à $60 \% \mathrm{VO}_{2 \text { pico }}$ ) e relataram redução na secreção de VLDL-ApoB100 sem alteração na taxa de secreção de VLDL-TAG. Os autores concluíram ainda que, o clearence da VLDL-TAG esta significantemente maior em decorrência do exercício o que mantém as concentrações plasmáticas de TAG menores, em comparação com o pré exercício. 
Makgos et al., (2008) compararam dois tipos de exercício (resistido ou endurance) em única sessão e demonstraram que diante do mesmo gasto calórico, uma sessão simples de exercício resistido (musculação) foi mais efetiva em reduzir a concentração de VLDLTAG plasmático em decorrência do maior remoção da partícula, além de maior taxa de oxidação lipídica nos indivíduos que executaram esse tipo de exercício.

Assim, considerando a importância da pratica de atividade física no combate a obesidade e dislipidemias são poucos os estudos que envolvem treinamento com exercícios de alta intensidade e sua interferência no metabolismo lipídico. A maior parte dos trabalhos examinam os exercícios ou treinamento de endurance, e nos poucos estudos com exercícios de alta intensidade os autores descrevem os efeitos de uma sessão simples, o que torna pouco explorado o conhecimento sobre exercícios intermitentes de alta intensidade e sua relação com o metabolismo lipídico. 


\section{Conclusão}

Ao final do trabalho concluímos que o grupo submetido ao treino que utilizou exercícios intermitentes de alta intensidade demonstra aumento na secreção de VLDLTAG pós exercício, mediado pelo possível aumento na expressão da MTP. Ainda a diminuição nos depósitos hepáticos de TAG e maior secreção de VLDL-TAG, sugerem maior transporte para a periferia com objetivo de repor depósitos de triacilglicerol intramuscular, fato que é corroborado pela obtenção de aumento na expressão gênica da LPL muscular. No que tange os demais parâmetros verificados ambos os treinamentos suscitaram adaptações semelhantes.

Assim, pode-se afirmar que esse tipo de atividade constitui interessante alternativa "time efficient" para a indução de alterações fisio-metabólicas desejáveis, mediadas pela atividade física crônica. 


\section{Referências Bibliográficas}

ABUMRAD, NA.; EL-MAGHRABI, MR.; AMRI, EZ.; LOPEZ, E.; GRIMALDI, PA. Cloning of a rat adipocyte membrane protein implicated in binding or transport of longchain fatty acids that is induced during preadipocyte differentiation. Homology with human CD36. J. Biol. Chem., v.268, n. 24, p. 17665-17668, 1993.

ACHTEN, J.; GLEESON, M.; JEUKENDRUP, AE. Determination of the exercise intensity that elicits maximal fat oxidation. Med. Sci. Sports. Exerc., v.34, n. 1, p. 92-97, 2002.

AGUILÓ, A.; TAULER, P.; VILLA, G.; CÓRDOVA, A.; TUR, JA.; PONS, A. Effect of exercise intensity and training on antioxidants and cholesterol profile in cyclists. J. Nutr. Biochem., v.14, n. 6, p. 319-325, 2003.

AHIMA, RS.; KELLY, J.; ELMQUIST, JK.; FLIER, JS. Distinct physiologic and neuronal responses to decreased leptin and mild hyperleptinemia. Endocrinology, v.140, n. 11, p. 4923-4931, 1999.

ALAM, S.; STOLINSKI, M.; PENTECOST, C.; BOROUJERDI, MA.; JONES, RH.; SONKSEN, PH.; UMPLEBY, AM. The effect of a six-month exercise program on very low-density lipoprotein apolipoprotein B secretion in type 2 diabetes. J. Clin. Endocrinol. Metab., v.89, n. 2, p. 688-694, 2004.

ALEXANDER, CA.; HAMILTON, RL.; HAVEL, RJ. Subcellular localization of B apoprotein of plasma lipoproteins in rat liver. J. Cell. Biol., v. 69, n. 2, p. 241-263, 1976.

ANGULO, P.; LINDOR, KD. Primary biliary cirrhosis and primary sclerosing cholangitis. Clin. Liver Dis., v. 3, n. 3, p. 529-570, 1999.

ANNUZZI, G.; JANSSON, E.; KAIJSER, L.; HOLMQUIST, L.; CARLSON, LA. Increased removal rate of exogenous triglycerides after prolonged exercise in man: time course and effect of exercise duration. Metabolism, v. 36, n. 5, p. 438-443, 1987.

ASP, L.; CLAESSON, C.; BOREN, J.; OLOFSSON, SO. ADP-ribosylation factor 1 and its activation of phospholipase D are important for the assembly of very low density lipoproteins. J. Biol. Chem., v. 275, n. 34, p. 26285-26292, 2000.

BABINEAU, C.; LÉGER, L. Physiological response of 5/1 intermittent aerobic exercise and its relationship to $5 \mathrm{~km}$ endurance performance. Int. J. Sports Med., v. 18, p. 13-19, 1997.

BACURAU, RF.; BELMONTE, MA.; SEELAENDER, MCL.; COSTA ROSA, LF. Effect of a moderate intensity exercise training protocol on the metabolism of macrophages and lymphocytes of tumor bearing rats. Cell. Biochem. Func., v. 18, n. 4, p. 249-258, 2000. 
BACURAU, RF.; HOMEM DE BITTENCOURT, PI.; NEWSHOLME, P.; COSTA, LF.; $\mathrm{R}$. Metabolic response of macrophages to injury promoted by the activated complement system. Cell. Biochem. Funct., v. 17, n. 3, p. 175-182, 1999.

BALDWIN, KM.; KLINKERFUSS, GH.; TERJUNG, RL.; MOLE, PA.; HOLLOSZY, JO. Respiratory capacity of white, red, and intermediate muscle: adaptative response to exercise. Am. J. Physiol., v. 222, n. 2, p. 373-378, 1972.

BANGSBO, J.; NORREGAARD, L.; THORSO, F. Activity profile of competition soccer. Can. J. Sport Sci., v.16, n 2, p. 110-116, 1991.

BARATTA, M. Leptin--from a signal of adiposity to a hormonal mediator in peripheral tissues. Med. Sci. Monit., v. 8, n. 12, p. RA282-292, 2002.

BARDEN, J.; LAWRENSON, L.; POOLE, JG.; KIM, J.; WRAY, DW.; BAILEY, DM.; RICHARDSON, RS. Limitations to vasodilatory capacity and .VO2 max in trained human skeletal muscle. Am. J. Physiol. Heart. Circ. Physiol., v. 292, n. 5, p. H2491-497, 2007.

BARRETT, PH.; WATTS, GF. Kinetic studies of lipoprotein metabolism in the metabolic syndrome including effects of nutritional interventions. Curr. Opin. Lipidol., n. 14, v. 1, p. 61-68, 2003.

BASS, NM. Function and regulation of hepatic and intestinal fatty acid binding proteins. Chem. Phys. Lipids, v. 38, n. 1-2, p. 95-114, 1985.

BELMONTE, MA.; AOKI, MS.; TAVARES, FL.; SEELAENDER, MC. Rat myocellular and perimysial intramuscular triacylglycerol: a histological approach. Med. Sci. Sports Exerc., v. 36, p. 60-67, 2004.

BERGASA, NV.; MEHLMAN, J.; BIR, K. Aerobic exercise: a potential therapeutic intervention for patients with liver disease. Med. Hypotheses., v. 62, n. 6, p. 935-941, 2004.

BERGER, J.; MOLLER, D. The mecanisms of action PPARs. Annual Rev. Med., v. 53, p. 409-435, 2002.

BERGERON, MF. Improving health through youth sports: is participation enough? New Dir. Youth Dev., n. 115, p. 27-41, 2007.

BERGERON, MF.; MARESH, CM.; KRAEMER, WJ.; ABRAHAM, A.; CONROY, B.; GABAREE, C. Tennis: A physiological profile during match play. Int. J. Sports Med., n. 5, p. 474-479, 1991.

BILLAT, LV., Interval training for performance: A scientific and empirical practice. Part I: Anaerobic interval training. Sports Med., v. 31, p. 13-31, 2001. 
BILLAT, LV. Interval training for performance: A scientific and empirical practice. Part II: Anaerobic interval training. Sports Med., v. 31, p. 75-90, 2001.

BJÖRNTORP, P. "Portal" adipose tissue as a generator of risk factors for cardiovascular disease and diabetes. Arteriosclerosis, v. 10, n. 4, p. 493-496, 1990.

BOBILLIER, CS.; MAUPOIL, V.; JACQUES LAHET, J.; BERTHELOT, A. Effect of exercise training on metallothionein levels of hypertensive rats. Med. Sci. Sports Exerc., v. 33, p. 724-728, 2001.

BONEN, A.; CAMPBELL, SE.; BENTON, CR.; CHABOWSKI, A.; COORT, SL.; HAN, XX.; KOONEN, DP.; GLATZ, JF.; LUIKEN, JJ. Regulation of fatty acid transport by fatty acid translocase/CD36. Proc. Nutr. Soc., v. 63, n. 2, p. 245-249, 2004.

BONEN, A.; LUIKEN, JJ.; ARUMUGAM, Y.; GLATZ, JF.; TANDON, NN. Acute regulation of fatty acid uptake involves the cellular redistribution of fatty acid translocase. J. Biol. Chem., v. 275, n. 19, p. 14501-14508, 2000.

BORBA-MURAD, GR.; DE SOUZA, HM.; LOPES, G.; FERREIRA, EB.; DAMBROSO, D.; BAZOTTE, RB. Changes in glycemia induced by exercise in rats: contribution of hepatic glycogenolysis and gluconeogenesis. Res. Commun. Mol. Pathol. Pharmacol., v. 102, p. 113-123, 1998.

BOSSAN, FM.; DOS ANJOS, LA.; LEITE DE VASCONCELLOS, MT.; WAHRLICH, V. Nutritional status of the adult population in Niterói, Rio de Janeiro, Brazil: the nutrition, physical activity, and health survey. Cad. Saúde Pública, n. 23, v. 8, p. 1867-1876, 2007

BREMER, J. The effect of fasting on the activity of liver carnitine palmitoyltransferase and its inhibition by malonyl-CoA. Biochim. Biophys. Acta, v. 665, p. 628-631, 1981.

BREMER, J.; NORUM, K.R. Palmityl Co-A: Carnitine O-palmityltranferase in the mitochondrial oxidation of palmityl Co-A. Eur. J. Biochem., v. 1, p. 427-433, 1967.

BROOKS, GA.; MERCIER, J. Balance of carbohydrate and lipid utilization during exercise: the "crossover" concept. J. Appl. Physiol., v. 76, n. 6, p. 2253-2261, 1994.

BROOKS, GA.; TRIMMER, JK. Glucose kinetics during high-intensity exercise and the crossover concept. J Appl Physiol., v. 80, n. 3, p. 1073-1075, 1996.

BURGOMASTER, KA.; HOWARTH, KR.; PHILLIPS, SM.; RAKOBOWCHUK, M.; MACDONALD, MJ.; MCGEE, SL.; GIBALA, MJ. Similar metabolic adaptations during exercise after low volume sprint interval and traditional endurance training in humans. J. Physiol., v. 586, n. 1, p. 151-160, 2008. 
CALBET, JA.; ROBACH, P.; LUNDBY, C.; BOUSHEL, R. Is pulmonary gas exchange during exercise in hypoxia impaired with the increase of cardiac output? Appl. Physiol. Nutr. Metab., v. 33, n. 3, p. 593-600, 2008.

CARLSON, LA.; ERICSSON, M. Quantitative and qualitative serum lipoprotein analysis. Part 1. Studies in healthy men and women. Atherosclerosis, v. 21, n. 3, p. 417-433, 1975.

CARNEVALI JUNIOR, LC. O PPAR alfa como mediador de alterações no metabolismo lipídico no músculo esquelético de ratos treinados. Dissertação (Mestrado em Ciências) - Instituto de Ciências Biomédicas, Universidade de São Paulo, São Paulo, 2006.

CHALDAKOV, GN.; STANKULOV, IS.; HRISTOVA, M.; GHENEV, PI. Adipobiology of disease: adipokines and adipokine-targeted pharmacology. Curr. Pharm. Des., v. 9, n. 12, p. 1023-1031, 2003.

CHAN, SY.; MANCINI, GB.; BURNS, S.; JOHNSON, FF.; BROZIC, AP.; KINGSBURY, K.; BARR, S.; KURAMOTO, L.; SCHULZER, M.; FROHLICH, J.; IGNASZEWSKI. A. Dietary measures and exercise training contribute to improvement of endothelial function and atherosclerosis even in patients given intensive pharmacologic therapy. J. Cardiopulm. Rehabil., n. 26, v. 5, p. 288-293, 2006.

CHAPADOS, NA.; SEELAENDER, M.; LEVY, E.; LAVOIE, JM. Effects of exercise training on hepatic microsomal triglyceride transfer protein content in rats. Horm. Metab. Res., v. 41, n. 4, p. 287-293, 2009.

CHARBONNEAU, A.; UNSON, CG.; LAVOIE, JM. High-fat diet-induced hepatic steatosis reduces glucagon receptor content in rat hepatocytes: potential interaction with acute exercise. J. Physiol., v. 579, p. 255-267, 2007.

CHILLIBECK, PD.; BELL, GJ.; FARRAR, RP.; MARTIN, TP. Higher mitochondrial fatty acid oxidation following intermittent versus continuous endurance exercise training. Can. J. Physiol. Pharmacol., v. 76, p. 891-894, 1998.

CLAVEL, S.; FAROUT, L.; BRIAND, M.; BRIAND, Y.; JOUANEL, P. Effect of endurance training and/or fish oil supplemented diet on cytoplasmic fatty acid binding protein in rat skeletal muscles and heart. Eur. J. Appl. Physiol., v. 87, n. 3, p. 193-201, 2002.

COGGAN, AR.; SPINA, RJ.; KING, DS.; ROGERS, MA.; BROWN, M.; NEMETH, PM.; HOLLOSZY, JO. Skeletal muscle adaptations to endurance training in 60- to 70-yr-old men and women. J. Appl. Physiol., n. 72, v. 5, p.1780-1786, 1992.

COGGAN, AR.; SWANSON, SC.; MENDENHALL, LA.; HABASH, DL.; KIEN, CL. Effect of endurance training on hepatic glycogenolysis and gluconeogenesis during prolonged exercise in men. Am. J. Physiol., v. 268, p. E375-383, 1995. 
COGGAN, AR.; WILLIAMS, BD. Metabolic adaptations to endurance training: substrate metabolism during exercise. Exercise metabolism. Champaign: Human Kinetics Publishers, 1995.

COSTILL, DL.; FINK, WJ.; GETCHELL, LH.; IVY, JL.; WITZMANN, FA. Lipid metabolism in skeletal muscle of endurance-trained males and females. J. Appl. Physiol., v. 47, n. 4, p. 787-791, 1979.

COSTILL, DL.; GOLLNICK, PD.; JANSSON, ED.; SALTIN, B.; STEIN, EM. Glycogen depletion pattern in human muscle fibers during distance running. Acta Physiol. Scand., v. 89, p. 374-383, 1973.

COYLE, EF. Very intense exercise-training is extremely potent and time efficient: a reminder. J. Appl. Physiol., v. 98, n. 6, p. 1983-1994, 2005.

CRYER, A. Tissue lipoprotein lipase activity and its action in lipoprotein metabolism. Int. J. Biochem., v. 13, n. 5, p. 525-541, 1981.

CULLINANE, E.; SICONOLFI, S.; SARITELLI, A.; THOMPSON, PD. Acute decrease in serum triglycerides with exercise: is there a threshold for an exercise effect? Metabolism, v. 31, n. 8, p. 844-847, 1982.

CUNHA, RR.; CUNHA, VN.; SEGUNDO, PR.; MOREIRA, SR.; KOKUBUN, E.; CAMPBELL, CS.; DE OLIVEIRA, RJ.; SIMÕES, HG. Determination of the lactate threshold and maximal blood lactate steady state intensity in aged rats. Cell. Biochem. Funct., v. 27, n. 6, p. 351-357, 2009.

CURI, R.; NEWSHOLME, P.; NEWSHOLME, EA. Metabolism of pyruvate by isolated rat mesenteric lymphocytes, lymphocyte mitochondria and isolated mouse macrophages. Biochem. J., v. 250, p. 383-388, 1988.

DENGEL, DR.; GALECKI, AT.; HAGBERG, JM.; PRATLEY, REA. The independent and combined effects of weight loss and aerobic exercise on blood pressure and oral glucose tolerance in older men. Am. J. Hypertens., v. 11, n. 12, p. 1405-1412, 1998.

DENGEL, DR.; HAGBERG, JM.; PRATLEY, RE.; ROGUS, EM.; GOLDBERG, APB. Improvements in blood pressure, glucose metabolism, and lipoprotein lipids after aerobic exercise plus weight loss in obese, hypertensive middle-aged men. Metabolism, v. 47, n. 9, p. 1075-1082, 1998.

DESGORCES, FD.; CHENNAOUI, M.; GOMEZ-MERINO, D.; DROGOU, C.; GUEZENNEC, CY. Leptin response to acute prolonged exercise after training in rowers. Eur. J. Appl. Physiol., v. 91, n. 5-6, p. 677-681, 2004. 
DESPRÉS, JP.; BOUCHARD, C.; SAVARD, R.; TREMBLAY, A.; MARCOTTE, M.; THÉRIAULT, G. Level of physical fitness and adipocyte lipolysis in humans. J. Appl. Physiol., v. 56, n. 5, p. 1157-1161, 1984.

DIZDAR, O.; ALYAMAÇ, E. Obesity: an endocrine tumor? Med. Hypotheses, n. 63, v. 5, p. 790-792, 2004.

DONNELLY, JE.; BLAIR, SN.; JAKICIC, JM.; MANORE, MM.; RANKIN, JW.; SMITH, BK. American College of Sports Medicine Position Stand. Appropriate physical activity intervention strategies for weight loss and prevention of weight regain for adults. Med. Sci. Sports Exerc., n. 41, v. 2, p.:459-471, 2009.

DONNELLY, KL.; SMITH, CI.; SCHWARZENBERG, SJ.; JESSURUN, J.; BOLDT, MD.; PARKS, EJ. Sources of fatty acids stored in liver and secreted via lipoproteins in patients with nonalcoholic fatty liver disease. J. Clin. Invest., v. 115, n. 5, p. 1343-1351, 2005 .

DRYNAN, L.; QUANT, PA.; ZAMMIT, VA. The role of changes in the sensitivity of hepatic mitochondrial overt carnitine palmitoyltransferase in determining the onset of the ketosis of starvation in the rat. Biochem. J., v. 318, p. 767-770, 1996.

DUERDEN, JM.; BARTLETT, SM.; GIBBONS, GF. Regulation of very-low-densitylipoprotein lipid secretion in hepatocyte cultures derived from diabetic animals. Biochem. J., v. 262, n. 1, p. 313-319, 1989.

DUMORTIER, M.; BRANDOU, F.; PEREZ-MARTIN, A.; FEDOU, C.; MERCIER, J.; BRUN, JF. Low intensity endurance exercise targeted for lipid oxidation improves body composition and insulin sensitivity in patients with the metabolic syndrome. Diabetes Metab., v. 29, n. 5, p. 509-518, 2003.

DURSTINE, JL.; FERGUSON, MA.; SZYMANSKI, LM.; DAVIS, PG.; ALDERSON, NL.; TROST, SG.; PATE, RR. Effect of a single session of exercise on lipoprotein(a). Med. Sci. Sports Exerc., v. 28, n. 10, p. 1277-1281, 1996.

DURSTINE, JL.; GRANDJEAN, PW.; COX, CA.; THOMPSON, PD. Lipids, lipoproteins, and exercise. J. Cardiopulm. Rehabil., v. 22, p. 385-398, 2002.

DURSTINE, JL.; THOMPSON, PD. Exercise in the treatment of lipid disorders. Cardiol. Clin., v. 19, n. 3, p. 471-488, 2001.

EATON, S.; ZAITOUN, AM.; RECORD, CO.; BARTLETT, K. Beta-Oxidation in human alcoholic and non-alcoholic hepatic steatosis. Clin. Sci., v. 90, n. 4, p. 307-313, 1996.

ESSÉN, B. Studies on the regulation of metabolism in human skeletal muscle using intermittent exercise as an experimental model. Acta Phisiol. Scand., v. 454, p. 1-32, 1978. 
ESSÉN, B.; HAGENFELDT, L.; KAIJSER, L. Utilization of blood-borne and intramuscular substrates during continuous and intermittent exercise in man. J. Physiol., v. 265, p. 489-506, 1977.

FABBRINI, E.; MOHAMMED, BS.; MAGKOS, F.; KORENBLAT, KM.; PATTERSON, BW.; KLEIN, S. Alterations in adipose tissue and hepatic lipid kinetics in obese men and women with nonalcoholic fatty liver disease. Gastroenterology, v. 134, p. 424-431, 2008.

FATOUROS, IG.; TOURNIS, S.; LEONTSINI, D.; JAMURTAS, AZ.; SXINA, M.; THOMAKOS, P.; MANOUSAKI, M.; DOUROUDOS, I.; TAXILDARIS, K.; MITRAKOU, A. Leptin and adiponectin responses in overweight inactive elderly following resistance training and detraining are intensity related. J. Clin. Endocrinol. Metab., v. 90, n. 11, p. 5970-5977, 2005.

FISHER, EA.; ZHOU, M.; MITCHELL, DM.; WU, X.; OMURA, S.; WANG, H.; GOLDBERG, AL.; GINSBERG, HN. The degradation of apolipoprotein B100 is mediated by the ubiquitin-proteasome pathway and involves heat shock protein 70. J. Biol. Chem., v. 272, n. 33, p. 20427-20434, 1997.

FISHER, RM.; COPPACK, SW.; HUMPHREYS, SM.; GIBBONS, GF.; FRAYN, KN. Human triacylglycerol-rich lipoprotein subfractions as substrates for lipoprotein lipase. Clin. Chim. Acta., v. 236, n. 1, p. 7-17, 1995.

FRASER, F.; ZAMMIT, VA. Enrichment of carnitine palmitoyl transferases I and II in the contact sites of rat liver mitochondria. Biochem. J., v. 15, p. 225-229, 1998.

FRAYN, KN.; ARNER, P.; YKI-JÄRVINEN, H. Fatty acid metabolism in adipose tissue, muscle and liver in health and disease. Essays Biochem., v. 42, p. 89-103, 2006.

FREUND, BJ.; SHIZURU, EM.; HASHIRO, GM.; CLAYBAUGH, JR. Hormonal, electrolyte, and renal responses to exercise are intensity dependent. J. Appl. Physiol., v. 70, n. 2, p. 900-906, 1991.

FRIEDEWALD, WT.; LEVY, RI.; FREDRICKSON, DS. Estimation of the concentration of low-density lipoprotein cholesterol in plasma, without use of the preparative ultracentrifuge. Clin. Chem., v. 18, p. 499-502, 1972.

FUKUDA, N.; ONTKO, JA. Interactions between fatty acid synthesis, oxidation, and esterification in the production of triglyceride-rich lipoproteins by the liver. J. Lipid Res., v. 25, n. 8, p. 831-842, 1984.

GAITANOS, GC.; WILlIAMS, C.; BOOBIS, LH.; BROOKS, S. Human muscle metabolism during intermittent maximal exercise. J. Appl. Physiol., v. 75, p. 712-719, 1993. 
GALASSETTI, P.; COKER, RH.; LACY, DB.; CHERRINGTON, AD.; WASSERMAN, DH. Prior exercise increases net hepatic glucose uptake during a glucose load. Am. J. Physiol., v. 276, n. 6, p. E1022-1029, 1999.

GAUTHIER, MS.; COUTURIER, K.; CHARBONNEAU, A.; LAVOIE, JM. Effects of introducing physical training in the course of a 16-week high-fat diet regimen on hepatic steatosis, adipose tissue fat accumulation, and plasma lipid profile. Int. J. Obes. Relat. Metab. Disord., v. 28, n. 8, p. 1064-1071, 2004.

GAUTHIER, MS.; COUTURIER, K.; LATOUR, JG.; LAVOIE, JM. Concurrent exercise prevents high-fat-diet-induced macrovesicular hepatic steatosis. J. Appl. Physiol., v. 94, n. 6, p. 2127-2134, 2003.

GIBALA, MJ. Molecular responses to high-intensity interval exercise. Appl. Physiol. Nutr. Metab., v. 34, n. 3, p. 428-432, 2009.

GIBALA, MJ.; LITTLE, JP.; VAN ESSEN, M.; WILKIN, GP.; BURGOMASTER, KA.; SAFDAR, A.; RAHA, S.; TARNOPOLSKY, MA. Short-term sprint interval versus traditional endurance training: similar initial adaptations in human skeletal muscle and exercise performance. J. Physiol., v. 575, p. 901-911, 2006.

GIBALA, MJ.; MCGEE, SL. Metabolic adaptations to short-term high-intensity interval training: a little pain for a lot of gain? Exerc. Sport Sci. Rev., v. 36, n. 2, p. 58-63, 2008.

GIBALA, MJ. Protein metabolism and endurance exercise. Sports Med., v. 37, n. 4-5, p. 337-340, 2007.

GIBBONS, GF.; ISLAM, K.; PEASE, RJ. Mobilisation of triacylglycerol stores. Biochim. Biophys. Acta, v. 1483, n. 1, p. 37-57, 2000.

GIBBONS, GF.; WIGGINS, D.; BROWN, AM.; HEBBACHI, AM. Synthesis and function of hepatic very-low-density lipoprotein. Biochem. Soc. Trans., v. 32, p. 59-64, 2004.

GIBBONS, LW.; BLAIR, SN.; COOPER, KH.; SMITH, M. Association between coronary heart disease risk factors and physical fitness in healthy adult women. Circulation, v. 67, n. 5, p. 977-983, 1983.

GLAISTER, M. Multiple sprint work : physiological responses, mechanisms of fatigue and the influence of aerobic fitness. Sports Med., v. 35, n. 9, p. 757-777, 2005.

GLATZ, JF.; VAN DER VUSSE, GJ. Cellular fatty acid-binding proteins: their function and physiological significance. Prog. Lipid Res., v. 35, n. 3, p. 243-282, 1996.

GOBATTO, CA.; DE MELLO, MA.; SIBUYA, CY.; DE AZEVEDO, JR.; DOS SANTOS, LA.; KOKUBUN, E. Maximal lactate steady state in rats submitted to swimming exercise. Comp. Biochem. Physiol. Mol. Integr. Physiol.. v. 130, p. 21-27, 2001. 
GORDON, DA. Recent advances in elucidating the role of the microsomal triglyceride transfer protein in apolipoprotein B lipoprotein assembly. Curr. Opin. Lipidol., v. 8, n. 3, p. 131-137, 1997.

GORSKI, J.; OSCAI, LB.; PALMER, WK. Hepatic lipid metabolism in exercise and training. Med. Sci. Sports Exerc., v. 22, n. 2, p. 213-221, 1990.

GRANDJEAN, PW.; CROUSE, SF.; O'BRIEN, BC.; ROHACK, JJ.; BROWN, JA. The effects of menopausal status and exercise training on serum lipids and the activities of intravascular enzymes related to lipid transport. Metabolism, v. 47, n. 4, p. 377-383, 1998.

GREEN, ED.; MAFFEI, M.; BRADEN, VV.; PROENCA, R.; DESILVA, U.; ZHANG, Y.; CHUA, SCJR.; LEIBEL, RL.; WEISSENBACH, J.; FRIEDMAN, JM. The human obese (OB) gene: RNA expression pattern and mapping on the physical, cytogenetic, and genetic maps of chromosome 7. Genome Res., v. 5, n. 1, p. 5-12, 1995.

HAN, XX.; CHABOWSKI, A.; TANDON, NN.; CALLES-ESCANDON, J.; GLATZ, JF.; LUIKEN, JJ.; BONEN, A. Metabolic challenges reveal impaired fatty acid metabolism and translocation of FAT/CD36 but not FABPpm in obese Zucker rat muscle. Am J Physiol Endocrinol. Metab., v. 293, n. 2, p. E566-575, 2007.

HARDMAN, AE.; LAWRENCE, JE.; HERD, SL. Postprandial lipemia in endurancetrained people during a short interruption to training. J. Appl. Physiol., v. 84, n. 6, p. 18951901, 1998.

HAVEL, RJ.; HAMILTON, RL. Hepatic catabolism of remnant lipoproteins: where the action is. Arterioscler. Thromb. Vasc. Biol., v. 24, n. 2, p. 213-215, 2004.

HENRIKSSON, J. Training induced adaptation of skeletal muscle and metabolism during submaximal exercise. J. Physiol., v. 270, p. 661-675, 1977.

HERD, SL.; HARDMAN, AE.; BOOBIS, LH.; CAIRNS, CJ. The effect of 13 weeks of running training followed by $9 \mathrm{~d}$ of detraining on postprandial lipaemia. Br. J. utr., v. 80, n. 1, p. 57-66, 1998.

HESSELINK,MK.; VAN BAAK,MA. Physical activity and health, novel concepts and new targets: report from the 12th Conference of the International Research Group on the Biochemistry of Exercise. Proc.Nutr.Soc., v. 63, n. 2, p. 189-17, 2004.

HOLLOSZY, JO.; OSCAI, LB.; DON, IJ.; MOLE, PA. Mitochondrial citric acid cycle and related enzymes: adaptive response to exercise. Biochem. Biophys. Res. Commun., v. 40, n. 6, p. 1368-1373, 1970.

HOLLOSZY, JO.; SKINNER, JS.; TORO, G.; CURETON, TK. Effects Of A Six Month Program Of Endurance Exercise On The Serum Lipids Of Middle-Aged Man. Am. J. Cardiol., v. 14, p. 753-760, 1964. 
HOLLOSZY, JO; COYLE, EF. Adaptations of skeletal muscle to endurance exercise and their metabolic consequences. J. Appl. Physiol., v. 56, p. 831-838, 1984.

HOLLOSZY, JO. Effects of exercise on mitochondrial oxygen uptake and respiratory enzime activity in skeletal muscle. J. Biol. Chem., v. 242, p. 2278-2282, 1967.

HOLLOWAY, GP.; LUIKEN, JJ.; GLATZ, JF.; SPRIET, LL.; BONEN, A. Contribution of FAT/CD36 to the regulation of skeletal muscle fatty acid oxidation: an overview. Acta Physiol., v. 194, n. 4, p. 293-309, 2008.

HOROWITZ, JF.; KLEIN, S. Lipid metabolism during exercise. Am. J. Clin. Nutr., v. 72, p. 558S-563S, 2000.

HOROWITZ, JF.; LEONE, TC.; FENG, W.; KELLY, DP.; KLEIN, S. Effect of endurance training on lipid metabolism in women: a potential role for PPAR $\alpha$ in the metabolic response to training. Am. J. Physiol. (Endocrinol. Metab.), v. 279, p. E348-E355, 2000.

HOWARD, BV. Lipoprotein metabolism in diabetes mellitus. J. Lipid. Res., v. 28, n. 6, p. 613-628, 1987.

HOWLETT, TA. Hormonal responses to exercise and training: a short review. Clin. Endocrinol., v. 26, n. 6, p. 723-742, 1987.

JACOBS, KA.; KRAUSS, RM.; FATTOR, JA.; HORNING, MA.; FRIEDLANDER, AL.; BAUER, TA.; HAGOBIAN, TA.; WOLFEL, EE.; BROOKS, GA. Endurance training has little effect on active muscle free fatty acid, lipoprotein cholesterol, or triglyceride net balances. Am. J. Physiol. Endocrinol. Metab., v. 291, n. 3, p. E656-665, 2006.

JAKICIC, JM.; CLARK, K.; COLEMAN, E.; DONNELLY, JE.; FOREYT, J.; MELANSON, E.; VOLEK, J.; VOLPE, SL. American College of Sports Medicine position stand. Appropriate intervention strategies for weight loss and prevention of weight regain for adults. Med. Sci. Sports Exerc., v. 33, n. 12, p. 2145-2156, 2001.

JANSSON, E.; KAIJSER, L. Substrate utilization and enzymes in skeletal muscle of extremely endurance-trained men. J. Appl. Physiol., v. 62, p. 999-1005, 1987.

JENSEN, MD. Fate of fatty acids at rest and during exercise: regulatory mechanisms. Acta Physiol. Scand., v. 178, p. 385-390, 2003.

JOLES, JA.; BIJLEVELD, C.; VAN TOL, A. Plasma triglyceride levels are higher in nephrotic than in analbuminemic rats despite a similar increase in hepatic triglyceride secretion. Kidney Int., v. 47, p. 566-572, 1995.

KANTOR, MA.; CULLINANE, EM.; SADY, SP.; HERBERT, PN.; THOMPSON, PD. Exercise acutely increases high density lipoprotein-cholesterol and lipoprotein lipase activity in trained and untrained men. Metabolism, v. 36, n. 2, p. 188-192, 1987. 
KAWANAKA, K.; TABATA, I.; HIGUSHI, M. Effects of high intensity intermittent swimming on glucose transport in rat epitrochlearis muscle. J. Appl. Physiol., v. 84, p. 1852-1857, 1998.

KELLEY, GA.; KELLEY, KS. Aerobic exercise and lipids and lipoproteins in men: a meta-analysis of randomized controlled trials. J. Mens Health Gend., v. 3, n. 1, p. 61-70, 2006.

KERNER, J.; HOPPEL, C. Fatty acid import into mitochondria. Biochim. Biophys. Acta., v. 1486, n. 1, p. 1-17, 2000.

KIENS, B.; ESSEN-GUSTAVSSON, B.; CHRISTENSEN, NJ.; SALTIN, B. Skeletal muscle substrate utilization during submaximal exercise in man: effect of endurance training. J. Physiol., v. 469, p. 459-478, 1993.

KIENS, B.; RICHTER, EA. Utilization of skeletal muscle triacylglycerol during postexercise recovery in humans. Am. J. Physiol., v. 275, p. E332-337, 1998.

KIENS, B.; ROEPSTORFF, C. Utilization of long-chain fatty acids in human skeletal muscle during exercise. Acta Physiol. Scand., v. 178, n. 4, p. 391-396, 2003.

KIENS, B. Effect of endurance training on fatty acid metabolism: local adaptations. Med. Sci. Sports Exerc., v. 29, n. 5, p. 640-645, 1997.

KJAER, M..Hepatic glucose production during exercise. Adv. Exp. Med. Biol., v. 441, p. 117-127, 1998.

KOPELMAN, PG. Obesity as a medical problem. Nature, v. 404, n. 6778, p. 635-643, 2000.

LAMON-FAVA, S.; MCNAMARA, JR.; FARBER, HW.; HILL, NS.; SCHAEFER, EJ. Acute changes in lipid, lipoprotein, apolipoprotein, and low-density lipoprotein particle size after an endurance triathlon. Metabolism, v. 38, n. 9, p. 921-935, 1989.

LAVOIE, JM.; GAUTHIER, MS. Regulation of fat metabolism in the liver: link to nonalcoholic hepatic steatosis and impact of physical exercise. Cell. Mol. Life. Sci., v. 63, p. 1393-1409, 2006.

LEONHARDT, M.; LANGHANS, W. Fatty acid oxidation and control of food intake. Physiol. Behav., v. 83, n. 4, p. 645-651, 2004.

LEVINE, BD.VO2max: what do we know, and what do we still need to know? J. Physiol., v. 586, n. 1, p. 25-34, 2008.

LEWIS, GF. Fatty acid regulation of very low density lipoprotein production. Curr. Opin. Lipidol., v. 8, n. 3, p. 146-153, 1997. 
LIMA, WP.; CARNEVALI, LC JR.; EDER, R.; COSTA ROSA, LF.; BACCHI, EM.; SEELAENDER, MC. Lipid metabolism in trained rats: effect of guarana (Paullinia cupana Mart.) supplementation. Clin. Nutr., v. 24, n. 6, p. 1019-1028, 2005.

LINDHOLM, A. What determines fuel selection in relation to exercise? Proc. Nutr. Soc., v. 54, n. 1, p. 275-282, 1995.

LIRA, FS.; TAVARES, FL.; YAMASHITA, AS.; KOYAMA, CH.; ALVES, MJ.; CAPERUTO, EC.; BATISTA, ML JR.; SEELAENDER, M. Effect of endurance training upon lipid metabolism in the liver of cachectic tumour-bearing rats. Cell Biochem. Funct., v. 26, n. 6, p. 701-708, 2008.

LOWRY, OH.; ROSENBOROUGH, NJ.; FARR, AL.; RANDALL, RJ. Protein measurements with the foln phenol reagent . J. Biol. Chem., v. 193, p. 265-269, 1951.

LUIKEN, JJ.; COORT, SL.; WILLEMS, J.; COUMANS, WA.; BONEN, A.; VAN DER VUSSE, GJ.; GLATZ, JF. Contraction-induced fatty acid translocase/CD36 translocation in rat cardiac myocytes is mediated through AMP-activated protein kinase signaling. Diabetes, v. 52, n. 7, p. 1627-1634, 2003.

LUIKEN, JJ.; WILLEMS, J.; COORT, SL.; COUMANS, WA.; BONEN, A.; VAN DER VUSSE, GJ.; GLATZ, JF. Effects of cAMP modulators on long-chain fatty-acid uptake and utilization by electrically stimulated rat cardiac myocytes. Biochem. J., v. 367, p. 881-887, 2002.

MACDOUGALL, JD.; HICKS, AL.; MACDONALD, JR.; MCKELVIE, RS.; GREEN, HJ.; SMITH KM. Muscle performance and enzymatic adaptations to sprint interval training. J. Appl. Physiol., n. 84, v. 6, p. 2138-2142, 1998.

MACHADO, M.; CORTEZ-PINTO, H. Non-alcoholic fatty liver disease and insulin resistance. Eur. J. Gastroenterol. Hepatol., v. 17, n. 8, p. 823-826, 2005.

MAGKOS, F.; TSEKOURAS, YE.; PRENTZAS, KI.; BASIOUKAS, KN.; MATSAMA, SG.; YANNI, AE.; KAVOURAS, SA.; SIDOSSIS, LS. Acute exercise-induced changes in basal VLDL-triglyceride kinetics leading to hypotriglyceridemia manifest more readily after resistance than endurance exercise. J. Appl. Physiol., v. 105, p. 1228-1236, 2008.

MAGKOS, F.; WRIGHT, DC.; PATTERSON, BW.; MOHAMMED, BS.; MITTENDORFER, B. Lipid metabolism response to a single, prolonged bout of endurance exercise in healthy young men. Am. J. Physiol. Endocrinol. Metab., v. 290, n. 2, p. E355$362,2006$.

MAGKOS, F. Basal very low-density lipoprotein metabolism in response to exercise: mechanisms of hypotriacylglycerolemia. Prog. Lipid Res., v. 48, n. 3-4, p. 171-190, 2009. 
MATSUMOTO, M.; OGAWA, W.; AKIMOTO, K.; INOUE, H.; MIYAKE, K.; FURUKAWA, K.; HAYASHI, Y.; IGUCHI, H.; MATSUKI, Y.; HIRAMATSU, R.; SHIMANO, H.; YAMADA, N.; OHNO, S.; KASUGA, M.; NODA, T. PKC lambda in liver mediates insulin-induced SREBP-1c expression and determines both hepatic lipid content and overall insulin sensitivity. J. Clin. Invest., v. 112, n. 6, p. 935-944, 2003.

MCGARRY, JD.; FOSTER, DW. In support of the roles of malonyl-CoA and carnitine acyltransferase $\mathrm{I}$ in the regulation of hepatic fatty acid oxidation and ketogenesis. J. Biol. Chem., v. 254, n. 17, p. 8163-8168, 1979.

MCGARRY, JD.; FOSTER, DW. Regulation of hepatic fatty acid oxidation and ketone body production. Annu. Rev. Biochem., v. 49:395-420, 1980.

MCGARRY, JD.; WOELTJE, KF.; KUWAJIMA, M.; FOSTER, DW. Regulation of ketogenesis and the renaissance of carnitine palmitoyltransferase. Diabetes Metab, Rev., v. 5, p. 271-284, 1989.

MISHKIN, S.; STEIN, L.; GATMAITAN, Z.; ARIAS, IM. The binding of fatty acids to cytoplasmic proteins: binding to $\mathrm{Z}$ protein in liver and other tissues of the rat. Biochem. Biophys. Res. Commun., v. 47, n. 5, p. 997-1003, 1972.

MOLÉ, PA.; OSCAI, LB.; HOLLOSZY, J. O . Increase in level of palmityl CoA sintetase, carnitine palmityltransferase and palmityl CoA dehydrogenase, and in the capacity to oxidize fatty acids. J. Clin. Invest., v. 50, p. 2323-2330, 1971.

MONDON, CE.; DOLKAS, CB.; TOBEY, T.; REAVEN, GM. Causes of the triglyceridelowering effect of exercise training in rats. J. Appl. Physiol., v. 57, p. 1466-1471, 1984.

MOTTA, VT. Bioquímica clínica para o laboratório. $1^{\mathrm{a}}$ ed. São Paulo: Educs, 2005.

MURTHY, MS.; PANDE, SV. Malonyl-CoA-sensitive and -insensitive carnitine palmitoyltransferase activities of microsomes are due to different proteins. J. Biol. Chem., v. 269, n. 28, p. 18283-18286, 1994.

NARAYAN, KA.; MCMULLEN, JJ.; BUTLER, DP; WAKEFIELD, T; CALHOUN, WK. Effect of exercise on tissue lipids and serum lipoproteins of rats fed two levels of fat. J. Nutr., v. 105, n. 5, p. 581-587, 1975.

ODLAND, LM; HEIGENHAUSER, GJ; WONG, D; HOLLIDGE-HORVAT, MG; SPRIET, LL. Effects of increased fat availability on fat-carbohydrate interaction during prolonged exercise in men. Am. J. Physiol., v. 274, p. R894-902, 1998.

OLOFSSON, SO; ASP, L.; BORÉN, J. The assembly and secretion of apolipoprotein Bcontaining lipoproteins. Curr. Opin. Lipidol., v. 10, n. 4, p. 341-346, 1999. 
OSCAI, LB.; HOLLOSZY, JO. Effects of weight changes produced by exercise, food restriction, or overeating on body composition. J. Clin. Invest., v. 48, n. 11, p. 2124-2128, 1969.

PATTERSON, CM.; DUNN-MEYNELL, AA.; LEVIN, BE. Three weeks of early-onset exercise prolongs obesity resistance in DIO rats after exercise cessation. Am. J. Physiol. Regul. Integr. Comp. Physiol., v. 294, n. 2, p. R290-301, 2008.

PHILLIPS, SM.; GREEN, HJ.; TARNOPOLSKY, MA.; HEIGENHAUSER, GF.; HILL, RE.; GRANT, SM. Effects of training duration on substrate turnover and oxidation during exercise. J. Appl. Physiol., v. 81, n. 5, p. 2182-2191, 1996.

POLAK, J.; KLIMCAKOVA, E.; MORO, C.; VIGUERIE, N.; BERLAN, M.; HEJNOVA, J.; RICHTEROVA, B.; KRAUS, I.; LANGIN, D.; STICH, V. Effect of aerobic training on plasma levels and subcutaneous abdominal adipose tissue gene expression of adiponectin, leptin, interleukin 6, and tumor necrosis factor alpha in obese women. Metabolism, v. 55, n. 10, p. 1375-1381, 2006.

POTTER, BJ.; SORRENTINO, D.; BERK, PD. Mechanisms of cellular uptake of free fatty acids. Annu. Rev. Nutr., v. 9:253-270, 1989.

RAKOBOWCHUK, M.; TANGUAY, S.; BURGOMASTER, KA.; HOWARTH, KR.; GIBALA, MJ.; MACDONALD, MJ. Sprint interval and traditional endurance training induce similar improvements in peripheral arterial stiffness and flow-mediated dilation in healthy humans. Am. J. Physiol. Regul. Integr. Comp. Physiol., v. 295, n. 1, p. R236242, 2008.

RASMUSSEN, BB.; WOLFE, RR. Regulation of fatty acid oxidation in skeletal muscle. Annu. Rev. Nutr., v. 19, p. 463-484, 1999.

REAVEN, GM.; CHEN, YD. Role of insulin in regulation of lipoprotein metabolism in diabetes. Diabetes Metab. Rev., v. 4, n. 7, p. 639-652, 1988.

REDINGER, RN. Is enhanced energy utilization the answer to prevention of excessive adiposity? J. Ky. Med. Assoc., v. 107, n. 6, p. 211-217, 2009.

ROMIJN, JA.; COYLE, EF.; SIDOSSIS, LS.; GASTALDELLI, A.; HOROWILTZ, JF.; ENDERT, E.; WOLFE, RR. Regulation of endogenous fat and carbohydrate metabolism in relation to exercise intensity and duration. Am. J. Physiol. (Endocrinol. Metab.), v. 265, n. 28, p. E380-E391, 1993.

ROMIJN, JA.; COYLE, EF.; SIDOSSIS, LS.; ZHANG, XJ.; WOLFE, RR. Relationship between fatty acid delivery and fatty acid oxidation during strenuous exercise. J. Appl. Physiol., v. 79, n. 6, p. 1939-1945, 1995. 
ROSA, EC.; ZANELLA, MT.; RIBEIRO, AB.; KOHLMANN JUNIOR, O. Visceral obesity, hypertension and cardio-renal risk: a review. Arq. Bras. Endocrinol. Metabol., v. 49, n. 2, p.196-204, 2005.

RYYSY, L.; HÄKKINEN, AM.; GOTO, T.; VEHKAVAARA, S.; WESTERBACKA, J.; HALAVAARA, J.; YKI-JÄRVINEN, H. Hepatic fat content and insulin action on free fatty acids and glucose metabolism rather than insulin absorption are associated with insulin requirements during insulin therapy in type 2 diabetic patients. Diabetes, v. 49, n. 5, p. 749-758, 2000.

SAHA, AK.; VAVVAS, D.; KUROWSKI, TG.; APAZIDIS, A.; WITTERS, LA.; SHAFRIR, E.; RUDERMAN, NB. Malonyl-CoA regulation in skeletal muscle: its link to cell citrate and the glucose-fatty acid cycle. Am. J. Physiol., v. 272, p. E641-648, 1997.

SAMBROOK, J.; FRITSCH, EF.; MANIATIS, T. Molecular cloning - an amnual. $2^{\text {nd }}$ edition. Cold Spring Habour Laboratory Press, New York, 1989

SARIS, WH.; BLAIR, SN.; VAN BAAK, MA.; EATON, SB.; DAVIES, PS.; DI PIETRO, L.; FOGELHOLM, M.; RISSANEN, A.; SCHOELLER, D.; SWINBURN, B.; TREMBLAY, A.; WESTERTERP, KR.; WYATT, H. How much physical activity is enough to prevent unhealthy weight gain? Obes. Rev., v. 4, n. 2, p. 101-114, 2003.

SCHAFFER, JE.; LODISH, HF. Expression cloning and characterization of a novel adipocyte long chain fatty acid transport protein. Cell., v. 79, n. 3, p. 427-436, 1994.

SEBURN, K.; COICOU, C.; GARDINER, P. Effects of altered muscle activation on oxidative enzyme activity in rat alpha-motoneurons. J. Appl. Physiol., n. 77, v. 5, p. 22692274, 1994.

SEELAENDER, MCL.; CURI, R.; COLQUHOUN, A.; WILLIAMS, JF.; ZAMMITT, VA. Carnitine palmitoyltranferase II activity is decreased in liver mitochondria of cachectic rats bearing the walker 256 carcinosarcoma: effect of indomethacin treatment. Bioch. Molec. Biology Int., v. 44, p. 185-193, 1998.

SEIP, RL.; MOULIN, P.; COCKE, T.; TALL, A.; KOHRT, WM.; MANKOWITZ, K.; SEMENKOVICH, CF.; OSTLUND, R.; SCHONFELD, G.Exercise training decreases plasma cholesteryl ester transfer protein. . Arterioscler. Thromb., v. 13, n. 9, p. 13591367, 1993.

SEIP, RL.; SEMENKOVICH, CF. Skeletal muscle lipoprotein lipase: molecular regulation and physiological effects in relation to exercise. Exerc. Sport Sci. Rev., v. 26, p. 191-218, 1998.

SENE-FIORESE, M.; DUARTE, FO.; SCARMAGNANI, FR.; CHEIK, NC.; MANZONI, MS.; NONAKA, KO.; ROSSI, EA.; DE OLIVEIRA DUARTE, AC.; DÂMASO, AR. 
Efficiency of intermittent exercise on adiposity and fatty liver in rats fed with high-fat diet. Obesity, v. 16, n. 10, p. 2217-2122, 2008.

SHELNESS, GS.; SELLERS, JA. Very-low-density lipoprotein assembly and secretion. Curr. Opin. Lipidol., v. 12, n. 2, p. 151-157, 2001.

SHEPHERD, J. Lipoprotein metabolism: an overview. Ann. Acad. Med. Singapore, v. 21, n. 1, p. 106-113, 1992.

SHOJAEE-MORADIE, F.; BAYNES, KC.; PENTECOST, C.; BELL, JD.; THOMAS, EL.; JACKSON, NC.; STOLINSKI, M.; WHYTE, M.; LOVELL, D.; BOWES, SB.; GIBNEY, J.; JONES, RH.; UMPLEBY, AM. Exercise training reduces fatty acid availability and improves the insulin sensitivity of glucose metabolism. Diabetologia, v. 50, p. 404-413, 2007.

SIDOSSIS, LS.; WOLFE, RR.; COGGAN, AR. Regulation of fatty acid oxidation in untrained vs. trained men during exercise. Am. J. Physiol., v. 274, n. 3 Pt 1, p. E510-515, 1998.

SIMKO, V.; KELLEY, RE. Effect of physical exercise on bile and red blood cell lipids in humans. Atherosclerosis, v. 32, n. 4, p. 423-434, 1979.

SPASSIANI, NA.; KUK, JL..Exercise and the fatty liver. Appl. Physiol. Nutr. Metab., v. 33, n. 4, p. 802-807, 2008.

STANSBIE, D.; BROWNSEY, RW.; CRETTAZ, M.; DENTON, RM. Acute effects in vivo of anti-insulin serum on rates of fatty acid synthesis and activities of acetyl-coenzyme A carboxylase and pyruvate dehydrogenase in liver and epididymal adipose tissue of fed rats. Biochem J., v. 160, p. 413-416, 1976.

STEFANICK, ML.; MACKEY, S.; SHEEHAN, M.; ELLSWORTH, N.; HASKELL, WL.; WOOD, PD. Effects of diet and exercise in men and postmenopausal women with low levels of HDL cholesterol and high levels of LDL cholesterol. . N. Engl. J. Med., v. 339, n. 1, p. 12-20, 1998.

STORCH, J.; THUMSER, AE. The fatty acid transport function of fatty acid-binding proteins. Biochim. Biophys. Acta., v. 1486, n. 1, p. 28-44, 2000.

SUH, SH.; PAIK, IY.; JACOBS, K. Regulation of blood glucose homeostasis during prolonged exercise. Mol. Cells., v. 23, n. 3, p. 272-279, 2007.

TAKAHASHI, H.; ASANO, K.; NAKAYAMA, H. Effect of endurance training under hypoxic condition on oxidative enzyme activity in rat skeletal muscle. Appl. Human Sci., v. 15, n. 3, p. 111-114, 1996. 
TALANIAN, JL.; GALLOWAY, SD.; HEIGENHAUSER, GJ.; BONEN, A.; SPRIET, LLJ. Two weeks of high-intensity aerobic interval training increases the capacity for fat oxidation during exercise in women. Appl. Physiol., v. 102, n. 4, p. 1439-1447, 2007.

TAVARES, FL.; SEELAENDER, MC. Hepatic denervation impairs the assembly and secretion of VLDL-TAG. Cell Biochem. Funct., v. 26, p. 557-565, 2008.

THOMPSON, PD.; CROUSE, SF..; GOODPASTER, B.; KELLEY, D.; MOYNA, N.; PESCATELLO, L. The acute versus the chronic response to exercise. Med. Sci. Sports Exerc., v. 33, p. S438-453, 2001.

THOMPSON, PD.; CULLINANE, E.; HENDERSON, LO.; HERBERT, PN. Acute effects of prolonged exercise on serum lipids. Metabolism, v. 29, n. 7, p. 662-665, 1980.

THOMPSON, PD.; FRANKLIN, BA.; BALADY, GJ.; BLAIR, SN.; CORRADO, D.; ESTES, NA 3RD.; FULTON, JE.; GORDON, NF.; HASKELL, WL.; LINK, MS.; MARON, BJ.; MITTLEMAN, MA.; PELLICCIA, A.; WENGER, NK.; WILLICH, SN.; COSTA, F. Exercise and acute cardiovascular events placing the risks into perspective: a scientific statement from the American Heart Association Council on Nutrition, Physical Activity, and Metabolism and the Council on Clinical Cardiology. Circulation, v. 115, n. 17, p. 2358-2368, 2007.

TIIKKAINEN, M.; BERGHOLM, R.; VEHKAVAARA, S.; RISSANEN, A.; HÄKKINEN, AM.; TAMMINEN, M.; TERAMO, K.; YKI-JÄRVINEN, H. Effects of identical weight loss on body composition and features of insulin resistance in obese women with high and low liver fat content. Diabetes, v. 52, n. 3, p. 701-707, 2003.

TOCK, L.; PRADO, WL.; CARANTI, DA.; CRISTOFALO, DM.; LEDERMAN, H.; FISBERG, M.; SIQUEIRA, KO.; STELLA, SG.; ANTUNES, HK.; CINTRA, IP.; TUFIK, S.; DE MELLO, MT.; DÂMASO, AR. Nonalcoholic fatty liver disease decrease in obese adolescents after multidisciplinary therapy. Eur. J. Gastroenterol. Hepatol., v. 18, n. 12, p. 1241-1245, 2006.

TOPPING, DL.; MAYES, PA. Insulin and non-esterified fatty acids. Acute regulators of lipogenesis in perfused rat liver. Biochem. J., v. 204, n. 2, p. 433-439, 1982.

TREMBLAY, A.; SIMONEAU, JA.; BOUCHARD, C. Impact of exercise intensity on body fatness and skeletal muscle metabolism. Metabolism, v. 43, n. 7, p. 814-818, 1994.

TSEKOURAS, YE.; MAGKOS, F.; KELLAS, Y.; BASIOUKAS, KN.; KAVOURAS, SA.; SIDOSSIS, LS. High-intensity interval aerobic training reduces hepatic very low-density lipoprotein-triglyceride secretion rate in men. Am. J. Physiol. Endocrinol. Metab., v. 295, n. 4, p. E851-858, 2008. 
TSETSONIS, NV.; HARDMAN, AE.; MASTANA, SS. Acute effects of exercise on postprandial lipemia: a comparative study in trained and untrained middle-aged women. Am. J. Clin. Nutr., v. 65, n. 2, p. 525-533, 1997.

TUNSTALL, RJ.; MEHAN, KA.; WADLEY, GD.; COLLIER, GR.; BONEN, A.; HARGREAVES, M.; CAMERON-SMITH, D. Exercise training increases lipid metabolism gene expression in human skeletal muscle. Am. J. Physiol., v. 283, p. E66-E72, 2002.

TUOMINEN, JA.; EBELING, P.; LAQUIER, FW.; HEIMAN, ML.; STEPHENS, T.; KOIVISTO, VA. Serum leptin concentration and fuel homeostasis in healthy man. Eur, J, Clin, Invest., v. 27, n. 3, p. 206-211, 1997.

TURCOTTE, LP.; RICHTER, EA.; KIENS, B. Increased plasma FFA uptake and oxidation during prolonged exercise in trained vs. untrained humans. Am. J. Physiol., v. 262, n. 6 Pt 1, p. E791-799, 1992.

UNGER, RH.; ZHOU, YT.; ORCI, L. Regulation of fatty acid homeostasis in cells: novel role of leptin. Proc. Natl. Acad. Sci. U S A., v. 96, n. 5, p. 2327-2332, 1999.

VALLE, A.; CATALÀ-NIELL, A.; COLOM, B.; GARCÍA-PALMER, FJ.; OLIVER, J.; ROCA, P. Sex-related differences in energy balance in response to caloric restriction. Am. J. Physiol. Endocrinol. Metab., v. 289, n. 1, p. E15-22, 2005.

VAN LOON, LJ.; GREENHAFF, PL.; CONSTANTIN-TEODOSIU, D.; SARIS, WH.; WAGENMAKERS, AJ..The effects of increasing exercise intensity on muscle fuel utilisation in humans. J. Physiol., v. 536, n. Pt 1, p. 295-304, 2001.

VIRU, A. Mobilisation of structural proteins during exercise. Sports Med., v. 4, n. 2, p. 95$128,1987$.

WAJCHENBERG, BL. Subcutaneous and visceral adipose tissue: their relation to the metabolic syndrome. Endocr. Rev., v. 21, n. 6, p. 697-738, 2000.

WASSERMAN, DH.; CHERRINGTON, AD. Hepatic fuel metabolism during muscular work: role and regulation. Am. J. Physiol., v. 260, p. E811-824, 1991.

WASSERMAN, DH.; SPALDING, JA.; BRACY, D.; LACY, DB.; CHERRINGTON, AD.Exercise-induced rise in glucagon and ketogenesis during prolonged muscular work. Diabetes, v. 38, n. 6, p. 799-807, 1989.

WASSERMAN, DH.; WILLIAMS, PE.; LACY, DB.; GREEN, DR.; CHERRINGTON, $\mathrm{AD}$. Importance of intrahepatic mechanisms to gluconeogenesis from alanine during exercise and recovery. Am. J. Physiol., v. 254, p. e518-e525, 1988. 
WESTERTERP, KR. Perception, passive overfeeding and energy metabolism. Physiol. Behav., v. 89, n. 1, p. 62-65, 2006.

WINDER, WW.; AROGYASAMI, J.; BARTON, RJ.; ELAYAN, IM.; VEHRS, PR. Muscle malonyl-CoA decreases during exercise. J. Appl. Physiol., v. 67, n. 6, p. 22302233, 1989.

WINDER, WW.; BALDWIN, KM.; HOLLOSZY, JO. Enzymes involved in ketone utilization in different types of muscle: adaptation to exercise. Eur. J. Biochem., v. 47, p. 461-467, 1974.

WINDMUELLER, HG.; SPAETH, AE. Regulated biosynthesis and divergent metabolism of three forms of hepatic apolipoprotein B in the rat. J. Lipid Res., v. 26, n. 1, p. 70-81, 1985.

WITTERS, LA.; WATTS, TD.; DANIELS, DL.; EVANS, JL. Insulin stimulates the dephosphorylation and activation of acetyl-CoA carboxylase. Proc. Natl. Acad. Sci. U S A., v. 85, n. 15, p. 5473-5477, 1988.

WOELTJE, KF.; KUWAJIMA, M.; FOSTER, DW.; MCGARRY, JD.Characterization of the mitochondrial carnitine palmitoyltransferase enzyme system. II. Use of detergents and antibodies. J. Biol. Chem., v. 262, n. 20, p. 9822-9827, 1987.

WOLFE, RR.; KLEIN, S.; CARRARO, F.; WEBER, JM. Role of triglyceride-fatty acid cycle in controlling fat metabolism in humans during and after exercise. Am. J. Physiol., v. 258, p. E382-389, 1990.

YKI-JÄRVINEN, H. Combination therapy with insulin and oral agents: optimizing glycemic control in patients with type 2 diabetes mellitus. Diabetes Metab. Res. Rev., v. 18, p. S77-81, 2002.

YOSHIDA, T.; WATARI, H. Metabolic consequences of repeated exercise in long distance runners. Eur. J. Appl. Physiol. Occup. Physiol., v. 67, p. 261-265, 1993.

ZAMMIT, VA.; CORSTORPHINE, CG. Altered release of carnitine palmitoyltransferase activity by digitonin from liver mitochondria of rats in different physiological states. Biochem. J., v. 230, n. 389-394, 1985.

ZAMMIT, VA.; NEWSHOLME, EA. Effects of calcium ions and adenosine diphosphate on the activities of NAD+-linked isocitrate dehydrogenase from the radular muscles of the whelk and flight muscles of insects. Biochem. J., v. 154, p. 677-687, 1976.

ZAMMIT, VA. Insulin and the partitioning of hepatic fatty acid metabolism. Biochem. Soc. Trans., v. 23, n. 3, p. 506-511, 1995. 
ZAMMIT, VA. Role of insulin in hepatic fatty acid partitioning: emerging concepts. Biochem. J., v. 314, p. 1-14, 1996.

ZAMMIT, VA..; NEWSHOLME, EA. The maximum activities of hexokinase, phosphorylase, phosphofructokinase, glycerol phosphates dehydrogenases, lactate dehydrogenase, octopine dehydrogenase, phosphoenolpyruvate carboxykinase, nucleoside diphosphokinase, glutamato-oxalacetate transaminase and arginine kinase in relation to carbohydrate utilization in muscles from marine invertebrates. Biochim. J., v. 160, p. 447$462,1976$.

ZAMMIT, VA. Carnitine acyltranferases: functional significance of subcellular distribution and membrane topology. Progr. Lipid Res., v. 38, p. 199-224, 1999.

ZHANG, Y., PROENCA, R., MAFFEI, M., BARONE, M., LEOPOLD, L., FRIEDMAN, J.M. Positional cloning of the mouse obese gene and its human homologue. Nature, v.372, p.425-432, 1994.

ZONDERLAND ML..; BÄR PR..; REIJNEVELD JC..; SPRUIJT BM..; KEIZER HA..; GLATZ JF. Different metabolic adaptation of heart and skeletal muscles to moderateintensity treadmill training in the rat. Eur J Appl Physiol Occup Physiol., v. 79, n. 5, p. 391-6, 1999. 